\title{
La violencia y El otro lado del sueñode Pedro Luis Prados $^{1}$
}

\section{Jaime Zambrano 2}

\author{
University of Central Arkansas, Estados Unidos
}

\begin{abstract}
$\mathbf{r}_{\text {esumen }}$
Es un análisis formal de los cuentos de El otro lado del sueño, de Pedro Luis Prados. El tema gira alrededor de la invasión de Panamá, por parte del ejército estadounidense, con la intención de deponer a Manuel Noriega en 1989. El estudio se centra en el tema de la violencia y en la forma como se incorpora en la ficción dándole un carácter peculiar, por el tratamiento histórico del tema que logra alejarse de la narración historicista. Aunque lo narrado tiene un carácter verosímil, la narrativa es una obra de ficción estéticamente lograda que descubre una nueva dimensión existencial yonírica del evento histórico.
\end{abstract}

\begin{abstract}
$\mathbf{a}_{\text {bstract }}$
This is a formal analysis of short stories in El otro lado del sueño, by Pedro Luis Prados. The main theme is the invasion of Panama by the U.S. army, with the intention of deposing Manuel Noriega in 1989. The study focuses on the theme of violence and on how it is incorporated into the work of fiction, giving these short stories unique character, due to their treatment of history which distinguishes them from historic fiction. Although the narrations have a verisimilar essence, the stories become an esthetic work of fiction that exhibits a new oneiric and existential dimension of the historical events.
\end{abstract}

Palabras clave: literatura panameña, cuento panameño contemporáneo, literatura y política

Keywords: Panamanian literature, contemporary Panamanian short story, literature and politics

1 Ponencia presentada en el XX Congreso Internacional de Literatura Centroamericana (ciLca) 2012. Recibido: 30 de marzo de 2011; aceptado: 12 de junio de 2011.

2 Correo electrónico: jaimez@uca.edu 
El otro lado del sueño ${ }^{3}$ es una colección de cuentos de Pedro Luis Prados, cuyo tema gira alrededor de la invasión de Panamá por las tropas norteamericanas ocurrida el 20 de diciembre de 1989. Una tenue voz omnisciente captura presagios, reacciones ante la muerte, evocaciones, miedo, rabia e impotencia frente a este infame ataque denominado irónicamente Operación Causa Justa.

Según Carlos Fong, hay cinco libros clave relacionados con la invasión del 20 de diciembre de 1989: Juan Garzón se va a la guerra (1992), de Moravia Ochoa; Las huellas de mis pasos (1993), de Pedro Rivera; Los ultrajados (1994), de Mario Augusto Rodríguez; El otro lado del sueño (2003), de Pedro Luis Prados; y Un milagro bastante raro (2008), de Víctor Manuel Rodríguez $\gg^{4}$. Para Fong, que «con su obra El otro lado del sueño, Pedro Luis Prados se suma a la lista de autores de ficción que tratan el tema de la invasión y nos ofrece un enfoque de las consecuencias psicológicas de la guerra sobre la población civil y los militares panameños a través de los personajes y su circunstancia existencial».

El otro lado del sueño es una colección importante de las letras panameñas y recibió el premio Ricardo Miró de cuento en 2002, cuyo jurado resaltó «la unidad temática y un manejo coherente y artísticamente válido... de una coyuntura decisiva de la historia panameña ${ }^{5}$. La narración omnisciente utilizando diferentes figuras retóricas hace alusión a la multitud de voces de individuos que sufrieron directa o indirectamente las consecuencias de la invasión y a la agonía de la lucha entre la vida y al muerte.

3 Pedro Luis Prados, El otro lado del sueño (Panamá: Editorial Mariano Arosemena (INAC), 2003).

4 Carlos Fong, Los planos de la realidad identitaria del discurso narrativo en tres cuentos de El otro lado del sueño de Pedro Luis Prados. 21 de dic. de 2008; 14 de enero de 2012, <http://songadas. blogspot.com/2008/12/ensayo-de-carlos-fong-sobre-3-cuentos.html\#!/2008/12/ensayo-de-carlosfong-sobre-3-cuentos.html> (2).

5 Cita en la carátula posterior de la colección El otro lado del sueño y atribuida a los jueces del Concurso Miró de Cuento 2002, Eraclio Zepeda, Héctor Rodríguez y Dimas Lidio Pitty. 


\section{Contexto histórico}

El contexto histórico es un factor insoslayable al estudiar estas obras. La invasión de Panamá - denominada por los Estados Unidos «Operación Causa Justa»—ocurrió durante la administración de George H. Bush diez años después de que fuera ratificado el tratado Torrijos-Carter de 2000, cuando transferirían el control del Canal de Panamá a Panamá. El general y dictador panameño Manuel Noriega fue depuesto y el presidente electo Guillermo Endara fue nombrado presidente.

Desde 1986, la administración Reagan había tratado de negociar con Noriega la entrega del poder después de que Noriega fuera acusado de ser participe y cómplice en el tráfico de drogas. En marzo de 1988 fracasó un intento de golpe de estado contra Noriega. En las elecciones de mayo de 1989 Guillermo Endara fue elegido presidente; sin embargo, Noriega declaró nula está elección por irregularidades y fraude electoral. En octubre de 1989 las fuerzas de Noriega pudieron resistir otro intento de golpe de estado liderado por Moisés Giroldi ${ }^{6}$.

El gobierno de Bush anunció que no negociaría con un traficante de drogas. Mientras el ambiente se deterioraba y llegaba a su clímax, el 16 de diciembre de 1989, Robert Paz, teniente de la Fuerza Marina estadounidense fue detenido por las fuerzas de Noriega y al tratar de escapar fue dado de baja ${ }^{7}$. Los Estados Unidos decidieron invadir Panamá y Bush adujo cuatro razones en su discurso de la mañana del 20 de diciembre de 1989: primera, para salvaguardar la vida de los ciudadanos norteamericanos en Panamá; segunda, para defender la democracia de Panamá; tercera, combatir el tráfico de droga; y el lavado de dinero durante la corrupta administración de Noriega; y cuarta, proteger la integridad del Tratado Torrijos-Carter

6 Lawrence A. Yates, The US Military Intervention in Panama: Origins, Planning and Crises Management: June 1987-December 1989 (Washington D.C.: Center of Military History, United States Army, 2008) 5.

7 Evan A. Huelfer, «The Battle for Coco Solo Panama 1989», Infantry Magazine 7 enero 2000: 14-21 (20). 
y la protección del Canal de Panamá. El uso de la fuerza militar contra Panamá recibió apoyo de ambos partidos y el apoyo del $80 \%$ del público estadounidense 9 .

La Operación Causa Justa incluyó una fuerza militar de 27.684 militares y 300 aviones ${ }^{10}$. Pocas horas después de que la invasión empezara, Guillermo Endara fue posesionado como nuevo presidente de Panamá. Noriega estuvo prófugo algunos días y desesperado pidió asilo político en la Misión Diplomática del Vaticano en Ciudad de Panamá, donde las fuerzas americanas pusieron música rock a todo volumen durante varios días. Noriega finalmente se entregó el 3 de enero de 1990 y fue inmediatamente trasladado a los Estados Unidos ${ }^{11}$. Es evidente que el grado de violencia y fuerza excesiva utilizada por las tropas norteamericanas fue una de las críticas a la operación. Aunque los norteamericanos perdieron sólo veintitrés militares y las fuerzas militares de Panamá doscientos cinco ${ }^{12}$; la cifra problemática es el número de civiles muertos. La Comisión para los Derechos Humanos de Centroamérica (codehuca) estima entre 2.500 y 3.000 civiles muertos a causa de la invasión. En su informe critica el alto número de muertos civiles panameños y la imprudencia de las fuerzas norteamericanas al no localizar cuidadosamente su ataque a objetivos militares. Aunque el $92 \%$ de los panameños apoyaban la invasión ${ }^{13}$, ésta fue repudiada internacionalmente. La Asamblea de las Naciones Unidas votó 75 a 20, para condenar la invasión como una violación del derecho internacional ${ }^{14}$. Brewer mantiene que el presidente Bush no estaba

8 «ATranscript of President Bush's Address on the Decision to Use Force», New York Times, 21 de dic. De 1989: 1-2 (1).

9 J. K. Cramer, «'Just Cause’ or Just Politics? U.S. Panama Invasion and Standardizing Qualitative Tests for Diversionary War», Armed Forces \& Society 9 de abril de 2006: 178-201.

10 Yates, 8.

11 Huelfer, 3.

12 Yates, 12.

13 Robert A. Pastor, Exiting the Whirlpool: U.S. Foreign Policy Toward Latin America and the Caribbean (Boulder: Westview Press, 2001) 96.

14 Pastor, 97. 
defendiendo el hemisferio contra una amenaza europea ni contra la amenaza del comunismo, sino que buscaba derrocar a un dictador por ser una amenaza a los Estados Unidos ${ }^{15}$.

Las consecuencias de la invasión fueron desastrosas para $\mathrm{Pa}$ namá. Además del alto número de muertos y heridos, 20.000 personas perdieron sus casas a causa del incendio en El Chorrillo. El 10 de febrero del 1990 el gobierno de Endara abolió el ejército de Panamá, ley que fue confirmada por un voto unánime parlamentario y una enmienda a la constitución panameña en 1994 que abolía el ejército en forma definitiva.

\section{La violencia}

La violencia es uno de los problemas fundamentales de Hispanoamérica. La ficción centroamericana y panameña refleja este hecho en las páginas de novelas y cuentos que son como la piel de los pueblos y los testigos de esta condición omnipresente. Una aproximación crítica al fenómeno de la violencia en la ficción la encontramos en Imaginación y violencia en América de Ariel Dorfman ${ }^{16}$, quien analiza tres tipos de violencia en el personaje de la literatura hispanoamericana: la violencia vertical o social, la violencia horizontal o individual y la violencia inespacial o interior.

La vertical es la violencia social de personajes que se rebelan contra la sociedad y en especial contra los que controlan el poder. La violencia social es la del oprimido que lucha por justicia social e igualdad: «Para construir se necesita primero destruir, para la paz se hace la guerra, a la explotación directa se responde con la violencia directa $»^{17}$. En la violencia vertical se encuentra la agresividad que ha servido de catalizador en las revoluciones. El personaje cuando se ha sentido atropellado y

15 Stewart Brewer, Borders and Bridges: A History of U.S.-Latin American Relations (Westport: Greenwood Press, 2006) 147.

16 Ariel Dorfman, Violencia e imaginación en América (Santiago de Chile: Editorial Universitaria, 1970).

17 Dorfman, 17. 
pisoteado se ha unido en torno a la violencia para cambiar la estructura social. La violencia vertical se da como una forma de salvación, donde sólo existiría condena sin ella. La verticalidad de la violencia muchas veces se pierde al horizontalizarse el fenómeno.

La violencia horizontal o individual se da cuando un personaje agrede a otro ser humano sin importar quien sea, por la razón que sea. La violencia no tiene un sentido social. Es ineludible, ya que el personaje no tiene otra opción: o mata o lo matan. El círculo vicioso de este tipo de violencia revela el poder mítico de la violencia, una fuerza invisible y poderosa que domina y controla al ser humano de tal forma que el personaje es enredado en ella, atrapado, incapaz de escapar, ni de controlarla: «abrumados por su situación, los personajes tratan de destruir a los seres que aman, como si con esto estuvieran castigándose por el hecho de existir, pateándose por dejarse atrapar en temblor de la existencia, sin poder hallar una solución o salida $»^{18}$. En El otro lado del sueño, la violencia horizontal se ilustra en la forma como los personajes que viven en El Chorrillo - un inmenso barrio deteriorado por el hacinamiento y la falta de higiene - se agreden entre sí, especialmente durante la borrachera. Esta violencia es una forma de existencia, parte integral de la realidad representada en los cuentos de Prados que a su paso engendra más violencia; los personajes están presos, limitados y condenados por ella. La violencia también es el acto unificador en la narrativa. Es el ser supremo que gobierna el personaje, lo moldea y determina su destino.

La violencia inespacial o interior es la violencia del personaje que «termina refugiándose en los repliegues de su interioridad, tratando de alejar toda acción mediante una pretendida indiferencia $»^{19}$. La violencia interior se dirige contra el mismo personaje, es la fuerza autodestructiva, que proviene del miedo y de la angustia existencial. La violencia inespacial se manifiesta en el personaje que muere de pena moral por ta muerte de algún ser querido. La angustia del personaje se transmuta

18 Dorfman, 25.

19 Dorfman, 32. 

y es dirigida interiormente hacia sí mismo. Se manifiesta también en el personaje que se suicida; escoge destruirse a sí mismo en vez de luchar. Este personaje dilucida que la violencia interior es la única solución, ya que con la violencia vertical no se resuelve nada y con la violencia horizontal, la resolución sería algo cobarde porque sólo perjudicaría a un ser querido y no al verdadero causante de la angustia.

La violencia que se incorpora en la narrativa de Pedro Luis Prados es un acto catártico. Esta violencia narrativa se adapta mediante el uso de innovaciones técnicas como la multifocación, la polifonía, el continuo fluir de la conciencia durante el sueño y una lengua imaginaria. La narrativa representa esta violencia transgrediendo las reglas y normas establecidas en la narrativa tradicional. $\mathrm{Al}$ incorporarse la violencia en la narrativa no se busca representar un mundo sosegado, sino el que sufre y padece, para develar la conciencia de un personaje perturbado. De esta forma la lengua de Pedro Luis Prados se torna imaginativa, barroca, llena de imágenes, figuras y metáforas originales. Un análisis de los cuentos de El otro lado del sueño revela que la violencia es uno de los elementos más importantes que se incorpora de forma paradigmática en la ficción.

\section{«Tras el lente de la espera»}

«Tras el lente de la espera» es el primer cuento de la colección. Tito Suira espera con su Remington 24 la invasión tendido en el fango con su cara embetunada de negro y carcomido por chitras y mosquitos, lo que contrasta con los recuerdos de su novia Carolina quien trabaja como prostituta a la salida de la base militar de Howard donde se cita con soldados norteamericanos para ganar algún dinero. La narración adquiere un aspecto onírico o más bien de pesadilla, al recordar Tito la noche en que fue inadvertidamente a la casa de Carolina y la sorprendió en el sofá con Bill, un soldado gringo de pelo rubio y grandes ojos azules. Cuando Carolina le dice que sólo es un amigo y se lo quiere presentar, Tito le responde: «iQué mierda me vas a presentar ese hijo 
de puta...Esos cabrones lo que quieren es invadirnos y pasárselas a todas ustedes por los cojones!» (17). En el desenlace, Tito dispara con desenfrenado arrebato porque en medio del caos y la confusión de la invasión sólo distinguía en su pasmoso furor el cabello rubio y los ojos azules de Bill: «su convicción de defender la patria fue cediendo a un odio visceral» (21). Los saltos temporales y la incorporación de la sinestesia en imágenes repetitivas le da un carácter onírico al cuento porque parece más un amargo sueño que quisiéramos borrar de la memoria y es a la vez una forma deviolencia interior.

\section{«La noche de la aves»}

En «La noche de la aves» Calixto se encarga de vigilar el Cuartel Central en El Chorrillo. La narrativa hace una analogía entre la vida de Calixto - quien tenía muy mala puntería y quien jamás pudo acertar a un pájaro- - y la noche de la invasión norteamericana, cuando en un acto heroico, dominado por el miedo y arriesgando su vida, logra con su fusil de dotación AK-47 derribar un helicóptero norteamericano Black Hawk. La noche anterior Calixto tiene una pesadilla que no entiende y es una premonición de lo que ocurriría en la madrugada del 20 de diciembre. En su sueño, Calixto sueña que certeramente dispara a un visitaflor, le extrae el corazón y como le había pedido su abuelo, se lo come crudo repitiendo las palabras secretas que le había enseñado «con el ojo miro, con la mano lanzo y en el corazón lo alcanzo» (29). La narrativa superpone el plano onírico y el plano imaginario con un discurso existencial para resaltar la violencia vertical que experimenta el pueblo. Los soldados panameños defienden el cuartel pero sus AK-47 «eran impotentes frente a la precisión de las máquinas [norteamericanas], y fueron cayendo uno tras otro en un esfuerzo inútil» (40).

Finalmente, las fuerzas norteamericanas toman control del Cuartel General. Los helicópteros bombardean el sector y estallan cohetes en el patio del cuartel haciendo estallar los talleres y el 
depósito de combustible, «se estremecieron cielo y tierra, abriendo un surco incandescente entre las casas y El Chorrillo ardía en llamas» (33). Calixto por su parte no puede creer que el sueño de toda su vida se había realizado, que finalmente había cazado su visitaflor aunque no podía saber dónde guardaba el corazón. El desenlace del cuento ejemplifica la violencia vertical cuando los soldados panameños apretujados, sudorosos y moribundos con las manos atadas a las espaldas son llevados al campo de concentración de Emperador.

\section{«La fiesta de Carmina»}

Se describe de forma cruda y realista la vida de los más menesterosos de la sociedad en «La fiesta de Carmina». Ella trabaja en el bar El Límite sirviendo licor a trabajadores del Canal, macheteros, fumigadores y recolectores de basura. El trabajo estaba malo por falta de clientes y es despedida de su empleo. Después de tomar alcohol con sus amigos en las destartaladas casas del Pedro Obarrio, termina en el Cementerio Amador, «bosque funerario de la opulencia y el egocentrismo en donde la muerte termina por igualar a sus huéspedes» (48). El cementerio «desde hacia tiempo era lugar guarida de un número creciente de vagabundos... huyendo de la policía» (49). Aquí se discute acaloradamente la posible invasión « $i N i$ que tratados ni que canal! El asunto es que el país está jodido, no hay trabajo y no hay plata» (47). En medio de la borrachera y atrapados en el mundo de la inconsciencia, evocando sueños e imágenes de la infancia, Carmina experimenta el caer de cohetes directamente sobre su cabeza y la ráfaga de las ametralladoras. Pronto se da cuenta que los bultos de hombres, mujeres y niños amontonados son «un amasijo de carne y sangre como no lo hubiera imaginado jamás» (52).

Para Carmina su fiesta en el cementerio se había trasformado en una prolongada y dolorosa pesadilla. Al tratar de huir se golpea en la cabeza. Extenuada, con un desorden mental causado por la irrealidad de la situación y el estupor del alcohol, fue recogida al igual que 
los otros civiles muertos en El Chorrillo y trasladada para depositar su cadáver en la morgue de Santo Tomás. Al llegar al hospital se llevaron una sorpresa al revisarle los signos vitales, y al darse cuenta que Carmina todavía estaba viva. Esta escena ejemplifica la violencia vertical porque las víctimas son indefensos civiles que fueron atacados sin ninguna causa. El dolor de Carmina es una alegoría del sufrimiento que experimentó el pueblo panameño.

Uno de los aciertos de El otro lado del sueño es que los cuentos exhiben una unidad temática, estilística y lingüística. Además de la violencia, el elemento onírico es un tema recurrente como un doble plano en que se desdobla el personaje y que muestra semejanza con los cuentos de Ojos de Perro azul de Gabriel García Márquez. En «La noche de las aves», Calixto está sumergido en un profundo sueño mientras devora el corazón del visitaflor que había matado. «el sueño de toda su vida se había realizado» (29), y después, «sobresaltado...se despertó presa de una indescriptible angustia, extrañado del sueño» (29). «En la fiesta de Carmina», ésta corre desesperada por el cementerio durante el bombardeo «atrapada en un sutil recorrido por evocadores ensueños» (51), y después cuando vio a sus amigos muertos en un amasijo de carne, «pensó que aún estaba durmiendo, que el dulce sueño se había convertido de pronto en una prolongada y dolorosa pesadilla de la que no podía despertar» (52). Su mundo y el de sus amigos se terminaba, $\mathrm{y}$ «su sueño por luminosos pasajes era la cruel paradoja de la encrucijada por la que habían atravesado miles de panameños bajo el fragor de la metralla» (52).

\section{«El negocio navideño»}

Ismael es el protagonista en «El negocio navideño», un hombre imperturbable ante los reveses de la vida. Se dedicaba a vender en la calle lo que puede. Un día pescado, otro día ropa del mercado negro, a veces bolillos de marihuana u otra sustancia de rápida salida; otras veces vendía electrodomésticos de oscura procedencia. Ismael ha comprado un equipo de sonido por doscientos dólares que es la envidia 
del barrio. La descripción detallada y del Sony AS 241 contrasta con la pobreza y la miseria de los vecinos del barrio. Estos sin embargo tienen tiempo de reunirse para compartir, tomar y bailar al ritmo de la salsa y el merengue. La narrativa incorpora elementos intertextuales de la música popular. Existe un paralelismo entre la canción «Ligia Elena» de Rubén Blades que relata la historia de una niña de bien que «se fuga con un trompetista de arrabal con el consiguiente escándalo familiar y las recriminaciones de la madre» (58) y la historia de Ismael quien está enamorado de Tania, una chica del barrio quien va a estudiar Derecho y cuya madre no quería que se relacionara con nadie del barrio, «¿Qué se creía ese negro buscavidas y malhablado?...¡Su hija no era pan de pobres!» (59). Ismael es un experto en música popular bailable y hace referencia a Eddy Palmieri, la orquesta Harlow y la orquesta de Bobby Valentín entre otras. La incorporación de la lengua vernácula en la narrativa es un claro ejemplo de solidaridad, de la pluma, del narrador que plasma la visión del mundo de personas doblemente marginadas por la pobreza y la violencia y de cómo positivamente se legitiman espacios marginados.

El desenlace es inesperado y en medio de la fiesta y la borrachera ocurre el bombardeo de El Chorrillo. Ismael sale corriendo hacia la casa de su hermana y lo único que le preocupa es salvar su equipo de sonido. Lo pone rápidamente en una caja de cartón, aparentemente más preocupado por su valiosa posesión que por su propia vida. Desafortunadamente una ráfaga de ametralladora alcanza la caja. Al llegar donde su hermana en Calidonia su equipo de sonido está destruido «en miles de astillas de plástico, los circuitos integrales descuartizados... no podía creer lo que estaba viendo» (66). Su cuñado al fondo repite con insistencia «El Chorrillo está ardiendo» (66).

\section{«La visita»}

La destrucción de una familia inocente de pescadores es el tema central de «La visita». El protagonista, Hortensio Salazar vive una 
tranquila vidacomo pescador en Río Hato. Su esposa Delmira padece de una bronquitis crónica y después de mucho esfuerzo logra llevarla al hospital en la ciudad. La narrativa está llena de premoniciones, un cielo gris y la tormenta son claros presagios para Hortensio de algo malo por venir «un estremecimiento que no era causado por el frío ni la lluvia le sacudió todo el cuerpo y provocó un ligero temblor en sus extremidades» (68). Cuando llega a la Ciudad de Panamá «el vendaval comenzaba a amainar, tuvo el terrible presentimiento de su muerte» (69). La narrativa utiliza un tiempo rememorativo y hay digresiones temporales cuando Hortensio recuerda como una tormenta hizo naufragar la embarcación donde viajaba hace muchos años. Al mismo tiempo se hace una analogía entre su esfuerzo por sobrevivir durante el naufragio y la situación de Panamá, «era posible que hubiera llevado otra existencia paralela en el vacío absoluto de la nada. Tal vez había sufrido los mismos dolorosos momentos, abrazado iguales ilusiones y temido similares amenazas» (74). Después del bombardeo Hortensio regresa a Río Hato y encuentra su pequeño rancho de esteras de caña brava y viejas hojas de zinc destruido «sólo humo saliendo de un profundo hoyo en la tierra y un terrible olor a sulfuro y tierra calcinada» (79).

\section{«El recordatorio»}

«El recordatorio» el cuento más débil de la colección, porque parece más un recuento periodístico que un cuento y por la proximidad histórica y narrativa con el evento relatado. En la primera parte del cuento seguimos la historia de Pipo quien era parte del corrupto sistema de Noriega. Pipo discute con su esposa la difícil situación de Panamá «Con la plata de mi pensión y con lo que tú ganas a malas alcanza para pagar el apartamento, la luz y la comida» (86). Sin embargo, el narrador abandona la historia de Pipo y se centra en los esfuerzos de los norteamericanos por mejorar su imagen en Panamá a través de la televisión y la radio, haciendo campañas publicitarias para calmar a la gente y apaciguar los ánimos exaltados de la población bombardeada 
por las tropas norteamericanas. El cuento reproduce las palabras y misivas al pueblo panameño del comandante en jefe del ejército de los Estados Unidos, General de Brigada Barry McCaffrey: «El general McCaffrey hizo entrega de recordatorios a un grupo de periodistas que contribuyeron al éxito de la Operación Causa Justa» (95).

\section{«El día del sepelio»}

En «El día del sepelio», el protagonista Anselmo Carrillo muere ahogado cuando va de cacería durante la época lluviosa y es arrastrado por la creciente. Al día siguiente lo hallaron enredado entre las horquetas de los troncos y los bejucos. Procedía del interior, sin parientes y con muy pocos amigos. Como muchos, se había instalado en un modesto caserío con la intención de sembrar arroz o maíz. Sin embargo, solo encontró pobreza, miseria, calor y finalmente su muerte. A su compadre Inocencio Recuero le correspondió organizar su sepelio e invitar al cura Chepo. Es evidente el tono anticlerical del cuento «Como saben que por acá no hay plata no quieren moverse de la sacristía...vaya a buscarlo para un rezo de rico y verá que hasta le salen alas» (100). El cura Chepe no llega y los lugareños mientras lo esperan deciden preparar café y empanadas, abrir una botella de seco y ponerse a jugar dominó (100). Elementos mágicos y fantásticos se incorporaran en la narración por ejemplo cuando el compadre Inocencio cree que «el muerto le respondía a gritos y con señas» (100). El ataúd era de roble sólido «con refuerzos en las esquinas, clavos de cuatro pulgadas y calafeteado las juntas con estopa de coco y brea» (97). En la mitad del sepelio comienza el bombardeo durante la invasión que «iluminó su alrededor con claridad matutina...al mismo tiempo que dos helicópteros descendían sobre el pequeño caserío» (101). Todos huyen asustados, «agazapados como animales al acecho» (102). «El temor de una muerte inminente cayó» (103) sobre ellos, aunque todavía no pueden entender que sucedía ni quiénes eran esos hombres terribles con la cara pintada de betún. Los soldados norteamericanos 
decidieron caprichosamente arrestar a los aldeanos enlutados y confiscar el ataúd. Sin embargo, los cables que amarraban la caja mortuoria con el helicóptero no pudieron sostenerla y el ataúd cayó en el río. Una vez en el río, milagrosamente la caja fue arrastrada por la corriente hacia un «mar oscuro y turbulento» (104). Los tres prisioneros musitaron con alegría: «iMi compadre no se dejó atrapar! ¡Qué hombre más bellaco!... ¡Dios se lo llevó a la Gloria!»(104).

\section{«El invitado navideño»}

«El invitado navideño» es un relato algo diferente a los otros, porque se incorpora un elemento erótico en la narrativa, pero insólitamente ocurre durante el bombardero. Es la historia de Alvarito quien debe visitar a su tía Cora durante las vacaciones de navidad para hacerle compañía como lo había hecho durante muchos años. Su tía solterona Cora no es su tía real, sino una compañera de estudios de su madre cuando asistía a la escuela normal. Durante esta visita Alvarito por primera vez nota la belleza de la Tía Cora «nunca se había fijado en los blanquísimos brazos descubiertos en los que se asomaban algunas pecas» (110). «El invitado navideño» se relaciona con el erotismo porque las sensuales escenas descritas son sexualmente explícitas y la narrativa hace un paralelo dicotómico entre la penetración sexual de la tía Cora y el bombardeo de la ciudad «irrumpió en ella como la aurora en el mundo, la alegría desenfrenada de la carne» (117). El orgasmo es como la explosión final «Sintió de golpe, los proyectiles de una batalla aplazada horadando la oscuridad de su vida y un bombardeo silencioso vertiendo en su cuerpo fluido e ignorado...» (118).

Además, el cuento presenta una intertextualidad metatextual, que para Gérard Genette, es «relación crítica que tiene un texto con otro $»^{20}$. En este cuento es la historia de El padrino «finalmente Michael

20 Gérard Genette, Palimpsestos. La literatura en segundo grado (Madrid: Taurus, 1982) 65. 
Corleone implacable padrino de la organización ordenó liquidar a su hermano Fredo, sacrificando su propia familia para mantener la imagen de hombre fuerte» (113). «El invitado navideño» también se desdobla en el plano onírico ya que Alvarito tiene una experiencia extracorpórea en la que en un sueño proyecta su psiquismo a otro lugar determinado. En esta proyección se hace visible la imagen de la persona proyectada quien es la tía Cora. Es durante el sueño que un desinhibido Alvarito logra primero seducir a la tía Cora, «se acostó de lado sobre la cama y se abandonó sutilmente a un viaje hacia el interior de sí...y los finos labios de la tía Cora que volvían a apretarse sobre su rostro» (113).

\section{¿Qué características comparten los cuentos?}

En primer lugar, cuestionan y examinan un evento traumático en la historia de Panamá a través de personajes, humildes de la clase baja, que en realidad no comprenden íntegramente la situación. El punto de vista es heterodiegético porque el narrador no participa como personaje en los cuentos. Además, es omnisciente porque el narrador tiene conocimiento de los pensamientos más íntimos de los personajes. El espacio geográfico es El Chorrillo, más específicamente, la calle 26, el Cuartel Central, el Cementerio Amador y la Cárcel Modelo. El cielo es gris y la naturaleza sombría y triste que pareciera presentir la invasión, es a la vez una proyección del estado interior de los personajes y opera como una prefiguración. Los cuentos siguen una cronología lineal y hay pocas digresiones o saltos temporales. La mayoría de los cuentos cubren aproximadamente un día. La estructura narrativa de los cuentos presenta párrafos breves desde la perspectiva del narrador heterodiegético, seguidos por diálogos efímeros que revelan aspectos significativos o transcendentales del conflicto.

Hay numerosas figuras retóricas y tropos literarios que se aprecian en los cuentos de Pedro Luis Prados. Uno es la elipsis que es la omisión de una palabra o idea pero sin que por eso se obscurezca el sentido del texto. Es lo entredicho, lo que se queda en el aire y lo que el 
lector no conoce y debe imaginar. Aunque es evidente el significado de lo narrado, no se puede subestimar la importancia de lo omitido en estos cuentos, por ejemplo, «la tía formuló las preguntas de siempre a las cuales él contestó con una docena de monosílabos o con movimientos de cabeza» (108). Otra figura retórica que se incorpora en la narración es la hipérbole, un tropo que consiste en exagerar, aumentando o disminuyendo lo narrado, de tal forma que el receptor le otorgue más importancia a la acción en sí y no a la cualidad de dicha acción. En El otro lado del sueño las hipérboles son exageraciones deliberadas con el objeto de plasmar en el lector una imagen difícil de olvidar, por ejemplo «una flotilla de helicópteros sobrevoló las calles de El Chorrillo... al tiempo que dejaba caer un par de bombas que estremecieron cielo y tierra, abriendo un surco incandescente sobre las casas»(33).

Además, la narrativa está enriquecida con metáforas novedosas y sorprendentes que le dan a la ficción un carácter particular y especial en un ambiente mágico y onírico donde se confunden el sueño con la realidad de la invasión, por ejemplo «atrapado en el mundo de la inconsciencia, recorriendo astrales distancias sin principio ni fin, dejó de preocuparse por las luces suspendidas que horadaban la oscuridad» (51). Mientras que en El otro lado del sueño, el realismo se encuentra en el modo de contar la traumática invasión norteamericana y la situación de Panamá a finales de 1989, el elemento mágico no representa más que unos detalles ordinarios de poca trascendencia. Así, los cuentos invitan al lector a menospreciar lo real y a apreciar lo extraordinario y sorprendente del heroísmo y estoicismopanameño.

Los cuentos de El otro lado del sueño ni honran a los héroes ni incriminan a los villanos de la historia, sino que engrandecen a personajes común y corriente, a los humildes y a los perdedores de El Chorrillo que fueron las víctimas inocentes de las bombas y balas perdidas. Estos representan la situación panameña antes de la invasión y las consecuencias en miles de personas que perdieron su vida o sus viviendas después de la invasión; La violencia vertical es más importante en estos cuentos que la horizontal porque es una fuerza 
superior invasora quien inflige la violencia en un barrio humilde donde los habitantes son víctimas inocentes.

Los cuentos exploran la dicotomía ficción-historia. Pero el punto de partida de la ficción de Prados no se halla en el plano de las dicotomías entre lo histórico y lo ficticio, sino en su interacción, sincretización y fusión, como pautas para entender un conjunto que albergue lo ficticio y lo histórico conjuntamente. En último término, la aproximación de la ficción de Prados se construye desde la esperanza de poder desmitificar, a través de los ojos del narrador lo que sucedió en Panamá a finales de 1989. Lo esencial al analizar sus cuentos no consiste tanto en verificar la rotunda presencia temática de la violencia en la realidad literaria panameña, sino en mostrar cómo la violencia ha creado una cosmovisión que no se encuentra en ningún otro lugar; cómo el hombre panameño ha enfrentado el problema de la violencia, de la invasión, y de su libertad; y cómo, derrotado o vencedor, ha sabido buscar en la violencia su ser más íntimo, su vínculo ambiguo o inmediato con los demás.

La explicación histórica, social, política e ideológica, de la violencia en Panamá, queda fuera del libro desde el punto de vista del discurso literario. Pero, El otro lado del sueño sirve como marco de referencia, y todo lector más o menos familiarizado con la problemática de la invasión de Panamá en 1989 se sentirá inexorablemente comprometido a penetrar en la interpretación que subyace en el texto.

\section{Conclusiones}

Los cuentos ilustran la tensión y la violencia que existe a raíz de las divergencias surgidas entre la cultura de la superstición y la invasión norteamericana en un momento en que Noriega era acusado por la comunidad internacional de ser participe y cómplice en el tráfico de drogas. La ficción y las imágenes violentas se convierten en una herramienta poderosa y manipulable. Las vivencias trágicas de los personajes se trasmutan en una alegoría de la situación de 
Panamá durante la invasión. La narrativa de Pedro Luis Prados funde la realidad narrativa con elementos mágicos y oníricos, no tanto para reconciliar esta discrepancia sino para exagerar su aparente discordancia. El reto que esto supone para la noción común de la realidad, lleva implícito un cuestionamiento de la verdad que a su vez cuestiona de manera deliberada la historia oficial y hasta la autoridad de los propios cuentos.

Para Carlos Fong «este libro de cuentos con tema de la invasión es el mejor logrado hasta ahora en la construcción de personajes verosímiles con una dimensión existencial y sobre todo, en el tratamiento histórico del tema que logra alejarse de la mera narración historicista y que ficcionaliza con inteligencia y creatividad $»^{21}$. 